\title{
Perfil da Ocorrência de Sorovares de Salmonella Spp Na Cadeia de Carne de Aves no Estado da Bahia, Brasil.
}

\author{
Marilia Costa (I), Celso Duarte Carvalho Filho (I), Elisa Teshima (II,I) \\ (I) UFBa - Faculdade de Farmácia (Rua Barão do Jeremoabo, n 147, Ondina. Salvador-Bahia), \\ (II) UEFS - Universidade Estadual de Feira de Santana-Bahia (BR-116, Km 3, Campo Limpo, \\ Feira de Santana-Bahia)
}

\section{Resumo}

A salmonelose é uma doença de prevalência cosmopolita, que causa prejuízos econômicos na economia mundial e danos de saúde na população. A principal via de transmissão para o homem é o consumo de alimentos contaminados com Salmonella spp., principalmente produtos avícolas e ovos, e os primeiros sintomas podem aparecer a partir de algumas horas após a ingestão destes. O objetivo deste trabalho foi investigar a ocorrência de possíveis sorotipos de Salmonella spp. presentes na cadeia da carne de frango, no Estado da Bahia. Foi realizada a quantificação de Salmonella spp. através do método de Número Mais Provável (NMP) em seis etapas do processo de abate de aves, por meio de seis coletas, de cinco amostras representativas do lote, que resultaram em 30 amostras-compostas de aves coletadas em diferentes pontos do abate, em 06 amostras de água coletadas do chiller, e ainda 06 amostras de carcaças de frango descongelado. Observou-se a ocorrência de quatro sorotipos deste patógeno, em ordem decrescente de incidência: Salmonella Senftenberg (42,85\%); Salmonella Hadar (37,14\%); Salmonella Cubana (14,28\%); e Salmonella Schwarzengrund $(8,57 \%)$. Na etapa de pré-resfriamento foram encontrados resultados positivos para todos os sorovares relatados neste estudo, e nas demais etapas da obtenção de carne de aves, houve variação na frequência. Apenas nas amostras da água do chiller não foram encontrados resultados positivos de Salmonella spp. Estudos mostram que a Salmonella Hadar tornou-se o segundo sorotipo mais prevalente isolado de pacientes no final 
da década de 70. A incidência de Salmonella Cubana sido relatada como um sorotipo raro que pode causar sérias e frequentes infecções fatais em crianças, idosos e pessoas imunodeprimidas. Quanto ao sorotipo Schwarzengrund, são quase inexistentes os trabalhos de isolamento específico deste sorotipo, pois trata-se de sorovar pouco frequente na avicultura e em surtos de toxinfecções alimentares no Brasil, embora seja descrito em casos de salmoneloses no sudeste da Ásia e principal fonte de contaminação de alimentos importados aos Estados Unidos. A Salmonella Senftenberg tem sido associada mais frequentemente com amostras coletadas nas granjas, como rações, insumos e cama de frangos. Assim, os resultados apresentados neste estudo, contribuem para pesquisas posteriores deste patógeno na cadeia de produção de carne de aves.

Palavras-Chave: Carne de aves, Salmonelose, Salmonella spp Agência de Fomento: Faculdade de Farmácia-UFBa 